\title{
Housing Conditions and Adolescents' Socioemotional Well-being: An Empirical Examination from China
}

\author{
Zheng Zhou ${ }^{1} \mathbb{D} \cdot$ Ying Ma $^{1} \cdot$ Wenbin Du ${ }^{1} \cdot$ Kaiji Zhou $^{2} \cdot$ Shaojie Qi ${ }^{1,3}$
}

Accepted: 9 September 2021 /Published online: 21 September 2021

(c) The Author(s) 2021

\begin{abstract}
This paper examines the association between housing and adolescents' socioemotional well-being in China using a large nationally representative dataset from the 2016 China Family Panel Studies (CFPS). The results showed that housing conditions were negatively correlated with adolescents' depression and positively correlated with subjective well-being when family income was controlled. However, homeownership did not predict adolescent's subjective well-being and depression. Adolescents living in urban areas have better socioemotional well-being than adolescents living in rural areas, as demonstrated by their higher subjective well-being, lower depression, and higher self-esteem. Both urban and rural adolescents were influenced by housing conditions in a similar pattern. In addition, self-esteem mediated the relationship between housing conditions and adolescents' socioemotional well-being. The results indicate that housing conditions are an important factor for policymakers to consider when promoting children's well-being in China.
\end{abstract}

Keywords Housing $\cdot$ Homeownership $\cdot$ Depression $\cdot$ Subjective well-being $\cdot$ Selfesteem

\section{Introduction}

Housing has been regarded as an important aspect of child well-being by the United Nations International Children's Emergency Fund (UNICEF, 2007, 2016) and the Organization for Economic Co-operation and Development (OECD, 2009). The housing environment includes overcrowding, housing quality and conditions (roof

Shaojie Qi

qishaojie@swufe.edu.cn

1 Research Institute of Social Development, Southwestern University of Finance and Economics, Chengdu, China

2 Sichuan Top IT Vocational Institute, Chengdu, China

3 Department of Social Work and Social Policy, Nanjing University, 163 Xianlin Boulevard, Xixia District, Nanjing 210023, Jiangsu Province, China 
leaking, humid walls/floor/foundation or rotten window frames, a dark home, the lack of bath or shower facilities, and the lack of an indoor flushing toilet for family members), the murder rate and air pollution. Poor housing conditions caused by social and economic inequality have been a notable social issue in both developed and developing countries. Housing, as a potential environmental factor that affects child well-being, has drawn increasing attention from social scientists (Cairney, 2005; Evans et al., 2002; Harkness \& Newman, 2005; Leventhal \& Newman, 2010; Solari \& Mare, 2012). Housing impacts an individual's social life in many aspects, such as health, security, privacy, and community resources (Solari \& Mare, 2012). Children might be particularly vulnerable to poor housing conditions because the space in the home is where they interact with family members, socialize, practice skills, and acquire knowledge (Newman, 2008). Especially for children, housing relates to many aspects of child well-being, such as cognitive development (Rollings et al., 2017), academic achievements (Goux \& Maurin, 2004), and psychological well-being (Fowler et al., 2015; Jelleyman \& Spencer, 2008). Bradshaw et al. (2013) found that the correlation of the housing environment and school-age children's subjective well-being was 0.61 based on the healthy behavior data reported by UNICEF. In addition, Rees and Bradshaw (2017) further reported a significant correlation between the variables related to housing and 11-year-old children's subjective wellbeing. As mentioned above, if the home environment is strained, children's development might be undermined in many ways. Therefore, poor living conditions can be a path that leads to the intergenerational transmission of social inequality (Solari and Mare, 2012).

China has gone through rapid development of the housing market in the past decades. After the implementation Reform and Opening-up Policy in China, the housing policy in China has changed from publicly subsidized housing to a relatively free housing market. The housing reforms increased the homeownership rate (Wang, 2011), and also caused a dramatic growth of the housing prices in urban China $(\mathrm{Hu}$, 2013). The rapid change in the Chinese housing market attracted researchers to investigate how housing impacts Chinese residents' well-being ( $\mathrm{Hu}, 2013$; Huang, 2018). Researchers also pointed out that the polarization of housing might be a notable social issue that would be detrimental to children's health, cognition, and behaviors (Huang, 2018; Huang \& Wang, 2017).

Most studies on the effect of housing on well-being have focused on adults and young children. Homeownership, house crowding, and house quality were found to have significant impacts on children's well-being (Evans et al., 2002; Harkness \& Newman, 2005; Leventhal \& Newman, 2010; Solari \& Mare, 2012). However, adolescents who are in the transition stage of socioemotional development (Shek and Siu, 2019) are mostly neglected by the line of research on the effects of housing on individual well-being. In addition, although China has the second-largest adolescent population in the world (UNICEF, 2013), there is a lack of studies on the effects of Chinese families' housing on adolescents' well-being. In recent decades, the increasing polarization of housing in China has been a notable social issue that can be detrimental to children's health, cognition, and behaviors (Huang, 2018; Huang \& Wang, 2017). Given that empirical findings on adolescent well-being in Chinese contexts are not systematic (Leung, \& Fung, 2021; Shek, 2014), testing how housing 
influences children in Chinese cultural backgrounds provides the opportunity to validate the relationship between housing and child well-being found in most Western cultures. Psychological research has been criticized as based on "WEIRD" samples that are constituted by "Western, educated, industrial, rich and democratic" participants (Henrich et al., 2010). As pointed out by Shek (2014), research in the field of quality of life has been dominated by scholars with Western cultural backgrounds. Although there was a special issue on the well-being of Chinese children published in the Applied Journal of Quality of Life in 2020, most of the samples in these papers of this special issue were adolescents from the Hong Kong area. Systematic research on the quality of life among mainland Chinese children is still lacking. Therefore, the present study aims to investigate the link between housing to adolescents' socioemotional well-being in the contemporary mainland China context.

\section{Housing and adolescents' well-being}

A house is not only a physical room but also a psychological space for child development. It provides comfort, privacy, and safety, which are all important for the healthy development of children. In general, inadequate housing conditions can impact psychological well-being in different ways. For example, overcrowding causes distress, and the improvement of house quality can effectively reduce an individual's mental distress (Clair, 2019). A longitudinal study found that house quality, especially overcrowding, was positively related to low-income women's psychological withdrawal and loneliness (Wells \& Harris, 2007). In addition, poor housing was found to be detrimental to children's physical health (Shenassa et al., 2004). Gifford and Lacombe (2006) found a similar effect of poor housing among primary school children after controlling for social status and other family and individual variables. Coley et al. (2013) used six- years of longitudinal data to investigate the effects of housing variables on child well-being and found that housing quality has the largest effect on child well-being, independent of the other aspects of housing, such as homeownership, house mobility, and housing subsidies. However, the relationship between homeownership and children's outcomes is mixed. For example, Huang (2018) found house poverty was related to Chinese children's poor academic achievement. A review on the relationship between housing and child outcomes pointed out that, it's not homeownership that directly predicts child outcomes, but family income, stability, and other socioeconomic factors that play a role in child outcomes (Leventhal \& Newman, 2010).

There are several plausible explanations for the relationship between housing and child development. First, poor housing quality is commonly related to economic hardships; therefore, it indirectly influences socioemotional functioning (Coley et al., 2013). According to ecological system theory, factors at different ecological levels impact the development of children's psychological characteristics (Bronfenbrenner, 1979). The home environment is the proximal settings that children interact with frequently; family and parental characteristics, neighborhoods, and social networks can directly or indirectly impact children's development (Leventhal \& Newman, 2010). Shek and Siu (2019) have also pointed out 
that economic factors, such as poor housing conditions, might be a risk factor that contributes to the negative development of adolescents. Therefore, poor housing conditions should have negative impacts on children's well-being and increase the risk of mental health issues such as depression. In addition, an adverse growing environment impedes the development of an individual's self-evaluation, such as their self-esteem (Wang et al., 2021), which has been found to impact an individual's well-being. For example, a longitudinal study found that self-efficacy and a positive identity negatively predicted adolescents' depression after one year (Zhou et al., 2020a, b, c) and were positively correlated with adolescents' life satisfaction (Zhou et al., 2020a, b, c). Therefore, self-esteem might be a mediator in the relationship between housing conditions and adolescent well-being. For Chinese people, a house is an important family asset and is regarded as a sign of social status. Living in a decent house makes Chinese people feel as though they have a "face" in their community (Dong \& Guo, 2017), which is essential to Chinese people's self-value system, including self-esteem (Cheng, 1986; Hwang et al., 2010). Therefore, self-esteem associated with housing conditions should also be a mediator between the relationship of housing and adolescent well-being.

However, although well-being research has been burgeoning in recent years (Diener, 1984; Dolan et al., 2008; Zhou et al., 2020a, b, c), the relationship between housing and well-being is largely underresearched. The limited empirical evidence on this issue has mostly been developed by researchers from Western, developed countries, such as the United States and England (Clair, 2019). China is an important and interesting case to study the relationship between housing and child well-being due to its long tradition of preferring homeownership and the rapid development of its housing market in recent years. Researchers found that owning a house significantly increases Chinese residents' life satisfaction $(\mathrm{Hu}$, 2013). However, few studies have investigated the relationship between housing and Chinese adolescents' well-being. Although in recent years there has been a rising concern regarding the issue of subjective well-being in China (Shek, 2010), the limited studies in the Chinese setting have mainly focused on the effects of income, social status, and employment on well-being (Zhou et al., 2020a, b, c), and few studies have considered the relationship between housing and well-being.

As mentioned above, although previous studies have already documented the effect of housing on children's well-being, gaps still exist. First, previous studies have mostly focused on the association of housing and health outcomes (Harville \& Rabito, 2018; Sandel \& Wright, 2006; Sandra \& Tama, 2018; Weitzman et al., 2013), and very few studies on the relationship of housing and developmental outcomes such as socioemotional functioning (Leventhal \& Newman, 2010). Second, most of the studies on housing and child development were conducted on Western cultures (Clair, 2019), which has been criticized as "WEIRD" (research based on Western, educated, industrial, rich and democratic participants) (Henrich et al., 2010). Research on the effect of housing in China is still limited. Third, in addition to the direct association of housing quality and adolescent well-being, studies on the indirect effect of housing on well-being are still lacking; therefore, the underlying mechanism of the effect of housing is not clear. 


\section{The Present Study}

This paper aims to fill the abovementioned gaps by investigating the association between housing and Chinese adolescents' socioemotional well-being using a large nationally representative dataset of the 2016 wave of the Chinese Family Panel Survey (CFPS). The aims of the present study are as follows. First, we aimed to investigate the relationship between housing and Chinese adolescents' subjective well-being and depression. Second, we aimed to test whether self-esteem mediates the effect of housing on adolescents' subjective well-being and depression. We considered housing conditions and homeownership as the independent variables. The dependent variables were subjective well-being and depression, two indicators of adolescent socioemotional well-being. Self-esteem was regarded as the mediator of the association between housing conditions and adolescent socioemotional wellbeing. Based on previous findings, the present study has the following hypotheses:

Hypothesis 1: Housing (indexed by house conditions and homeownership) is positively associated with subjective well-being and negatively associated with depression.

Hypothesis 2: Housing (indexed by house conditions and homeownership) is positively associated with self-esteem;

Hypothesis 3: Self-esteem mediates the effect of housing on adolescents' subjective well-being and depression.

\section{Methods}

\section{Data and Sample}

To test the relationship between housing and adolescents' socioemotional wellbeing, the study analyzed the dataset of the 2016 CFPS. The CFPS is a longitudinal, nationwide survey of individuals and families in China. It started in 2010 and continued collecting data biennially thereafter. The sample of the CFPS was taken from 35 provinces and regions in Mainland China and covered $95 \%$ of the population of the nation. The CFPS survey included questions on household economic activities, education, family relationships, immigration, physical health, and mental health. In total, the 2016 CFPS included 45,369 individuals and 14,764 households. Because only children above 10 years old answered the depression questions, we selected children from ages 10 to 15 in the sample, and the final sample size for the depression analysis was 2,583. The sample characteristics are shown in Table 1.

As shown in the table, the sample included 1,391 boys and 1,192 girls. Regarding location, $59.0 \%$ of the respondents were from rural areas, and $40.1 \%$ of them were from urban areas in China. In addition, $59.4 \%$ of the children were in the high grades of primary schools, $36.8 \%$ of the children were in middle school, and $1.3 \%$ of the children were studying at high school or vocational school. The average net asset of the respondent's family was 509,704.83 Renminbi (approximately 72,814 US dollars). 
Table 1 Descriptive statistics of sample respondents

\begin{tabular}{|c|c|c|}
\hline Demographic information & $\mathrm{N}$ & Percentage \\
\hline \multicolumn{3}{|l|}{ Gender } \\
\hline Male & 1391 & 53.9 \\
\hline Female & 1192 & 46.1 \\
\hline \multicolumn{3}{|l|}{ Residence } \\
\hline Rural & 1525 & 59.0 \\
\hline Urban & 1035 & 40.1 \\
\hline Missing & 23 & 0.9 \\
\hline \multicolumn{3}{|l|}{ Recent education status } \\
\hline Primary school & 1534 & 59.4 \\
\hline Middle school & 951 & 36.8 \\
\hline Highschool/vocational school & 33 & 1.3 \\
\hline Missing & 65 & 2.5 \\
\hline \multicolumn{3}{|l|}{ Housing type } \\
\hline Cottage & 1035 & 40.1 \\
\hline Block & 368 & 14.2 \\
\hline Flat & 731 & 28.3 \\
\hline Quadrangle dwelling & 107 & 4.1 \\
\hline Terraced house & 7 & 0.3 \\
\hline Villa & 14 & 0.5 \\
\hline \multicolumn{3}{|l|}{ House ownership } \\
\hline Full- or partly-owned & 1740 & 67.4 \\
\hline No ownership & 238 & 9.2 \\
\hline Missing/not applicable & 605 & 23.4 \\
\hline Age & $N=2583, \mathrm{M}=12.390$ & $\mathrm{SD}=1.688$ \\
\hline $10-11$ & 922 & 35.69 \\
\hline $12-13$ & 851 & 32.95 \\
\hline $14-15$ & 810 & 31.36 \\
\hline Net asset(RMB) & $N=2497, \mathrm{M}=509,704.83$ & $\mathrm{SD}=1,461,233.507$ \\
\hline Income per family & $N=2549, \mathrm{M}=73,587.853$ & $\mathrm{SD}=202,558.479$ \\
\hline
\end{tabular}

\section{Dependent Variables}

We consider two indicators of adolescent socioemotional well-being: depression and subjective well-being. All the variables were available in the 2016 CFPS dataset.

Depression Measure CFPS 2016 adopted a simplified 8-item scale of the Center for Epidemiologic Studies Depression Scale (CES-D) to measure depression. The original CES-D scale developed by Radloff (1977) included 20 items asking questions regarding children's mental condition in the past one week. Examples included "I feel lonely" and "I can't sleep well". Children were asked how frequently they experienced the described feelings and then to rate their answers on a scale ranging from 
very rare (1) to most of the time (4). In the data collection process, researchers used an 8 -item scale with $80 \%$ of the respondents and an original 20 -item scale with $20 \%$ of the respondents. By using the equipercentile equating method, CFPS 2016 created a score of the simplified CES-D that is comparable to the original score of the CES-D. The present study used the created score of the CES-D as the indicator of children's depression.

Subjective Well-Being Measure Subjective well-being was measured by one item in the survey that asked the children how happy they were. The answers were rated using a 10-point Likert scale ranging from very unhappy (1) to very happy (10).

\section{Independent Variables}

The independent variables in the present study are housing conditions and homeownership. Four items measured the housing conditions of a family. The items were rated by the interviewers who entered the house and conducted the interviews with the family member. The four items included interior finishing (i.e., "how is the interior finishing of the living place of the interviewee?"), tidiness (i.e., "how tidy is the living place of the interviewee?"), domestic appliances and furnishings (i.e., "how are the domestic appliances and furnishings in the living place of the interviewee?"), and crowding (i.e., "how is the crowding of the living place of the interviewee?"). For the interior finishing item, the interviewer rated the living place using a 7-point Likert scale ranging from very shabby (1) to very splendid (7). For the tidiness item, the interviewer rated the place using a 7-point Likert scale ranging from very messy (1) to very tidy (7). For the domestic appliances and furnishings item, the interviewer rated the living place using a 7-point Likert scale ranging from very rare (1) to very rich (7). For the crowding item, the interviewer rated the place using a 7-point Likert scale ranging from very crowded (1) to very commodious (7). We computed the score of housing conditions by adding the scores of the four items. The Cronbach's $\alpha$ of the four items was 0.86, which suggested the high internal reliability of the measurement.

We also considered homeownership as a predictor of adolescents' well-being. Homeownership was categorized into two types: self-owned and no ownership. Both full ownership and shared ownership of the house were identified as self-owned, and other situations, such as renting a house or living in a house provided by a company or institution but not having ownership, were identified as no ownership.

\section{Mediator}

Self-Esteem Measure Self-esteem was measured by the Chinese self-esteem scale (translated from Rosenberg, 1965), including 10 items that were rated from very unlikely (1) to very likely (10). The Cronbach's $\alpha$ of the scale in this study was 0.70 , suggesting that the internal reliability is acceptable. 


\section{Control Variables}

We include demographic and socioeconomic control variables to model the association between housing conditions and child well-being. Adolescents' gender and age were the demographic variables that were controlled. Adolescents'residence and family income were socioeconomic variables that were also controlled in the model.

\section{Analysis}

Multiple linear regression was applied to examine the association of homeownership and housing conditions with children's depression and subjective well-being. First, children's demographic indicators were entered in the regression model, then the socioeconomic indicators were entered, and homeownership and housing conditions were entered in the last step. A listwise deletion approach was used to treat the cases with missing data. To examine the mediation effect, the PROCESS macro in SPSS (Preacher \& Hayes, 2008) was employed.

\section{Results}

\section{Descriptive Statistics of the Respondents' Socioemotional Well-Being}

The characteristics of adolescents' subjective well-being, depression and self-esteem are displayed in Table 2 under different residence categories. The mean subjective well-being was $8.265(S D=2.104)$, indicating that the average subjective wellbeing of the respondents was relatively high. As shown in Table 2, adolescents

Table 2 Characteristics of the respondents' socio-emotional well-being, China Family Studies, 2016

\begin{tabular}{|c|c|c|c|c|c|}
\hline & & $N$ & $M$ & $S D$ & $t$ \\
\hline \multirow[t]{5}{*}{ Subjective well-being } & Rural & 646 & 8.113 & 2.194 & $-2.790 * *$ \\
\hline & Urban & 482 & 8.461 & 1.972 & \\
\hline & Girls & 516 & 8.475 & 2.032 & $3.070 * *$ \\
\hline & Boys & 622 & 8.092 & 2.147 & \\
\hline & Total & 1138 & 8.265 & 2.104 & \\
\hline \multirow[t]{5}{*}{ Depression } & Rural & 1463 & 30.439 & 6.072 & $2.632 * *$ \\
\hline & Urban & 1004 & 29.795 & 5.820 & \\
\hline & Girls & 1144 & 30.490 & 6.148 & $2.366^{*}$ \\
\hline & Boys & 1343 & 29.921 & 5.837 & \\
\hline & Total & 2487 & 30.183 & 5.987 & \\
\hline \multirow[t]{5}{*}{ Self-esteem } & Rural & 648 & 3.792 & 0.387 & $-5.328 * * *$ \\
\hline & Urban & 482 & 3.926 & 0.442 & \\
\hline & Girls & 517 & 3.818 & 0.382 & $-2.459 *$ \\
\hline & Boys & 623 & 3.878 & 0.441 & \\
\hline & Total & 1140 & 3.851 & 0.417 & \\
\hline
\end{tabular}


from urban areas $(M=8.461, S D=1.972)$ felt significantly happier than adolescents from rural areas $(M=8.113, S D=2.194), p=0.005$, Cohen's $d=0.236$. The mean depression score was $30.182(\mathrm{SD}=5.987)$, and adolescents from urban areas $(M=29.795, S D=5.820)$ had less depression symptom than children from rural areas $(M=30.439, S D=6.072), p=0.009$, Cohen's $d=-0.153$. The mean selfesteem was $3.851(S D=0.417$, and urban adolescents $(M=3.926, S D=0.442)$ also showed a higher level of self-esteem than rural adolescents $(M=3.792, S D=0.387)$, $p<0.001$, Cohen's $d=0.458$. In general, adolescents living in urban areas have better socioemotional well-being than adolescents living in rural areas, as demonstrated by their higher subjective well-being, lower depression and higher self-esteem.

In terms of the differences by gender, girls $(M=8.475, S D=2.032)$ felt significantly happier than boys $(M=8.092, S D=2.147), p=0.002$, Cohen's $d=0.259$; however, girls $(M=30.490, \mathrm{SD}=6.148)$ had higher depression than boys $(M=29.921$, $S D=5.837), p=0.018$, Cohen's $d=0.134$, and girls $(M=3.818, S D=0.383)$ also showed a lower level of self-esteem than boys $(M=3.878, S D=0.441), p=0.014$, Cohen's $d=-0.206$.

\section{Interrelations Among the Variables}

Table 3 provides descriptive data and the interrelations among the variables. As shown in Table 3, subjective well-being was negatively correlated with depression and age and positively correlated with self-esteem, housing conditions, and family income. Depression was negatively correlated with subjective well-being, depression, housing conditions, and income and positively correlated with age. Self-esteem was positively correlated with subjective well-being and housing conditions.

\section{Regression of Housing and Subjective Well-Being}

To examine the unique effect of housing on children's subjective well-being, we regressed subjective well-being on homeownership and house conditions after controlling for demographic variables (age and gender) and socioeconomic variables (residence and family income). Gender was dummy coded as 0 (female) and 1 (male). The residence was dummy coded as 0 (rural) and 1 (urban). Housing conditions, family income, and age were mean-centered. Table 4 shows the results of

Table 3 Descriptive statistics and zero-order correlations of the key variables

\begin{tabular}{lcccllll}
\hline Variable & Mean & SD & 2 & 3 & 4 & 5 & 6 \\
\hline 1. well-being & 8.265 & 2.104 & $-.318^{* *}$ & $.212^{* *}$ & $.208^{* *}$ & $.088^{* *}$ & $-.104^{* *}$ \\
2.depression & 30.183 & 5.987 & & $-.274^{* *}$ & $-.076^{* *}$ & $-.044^{*}$ & $.087^{* *}$ \\
3. self-esteem & 3.851 & 0.416 & & & $.103^{* *}$ & $.085^{* *}$ & .055 \\
4. housing & 16.988 & 4.809 & & & & $.129^{* *}$ & .026 \\
5. income & $73,587.853 \mathrm{RMB}$ & $202,558.479 \mathrm{RMB}$ & & & & -.012 \\
6. age & 12.390 & 1.688 & & & & \\
\hline
\end{tabular}

${ }^{*} p<0.05, * * p<0.01, * * * p<0.001$ 


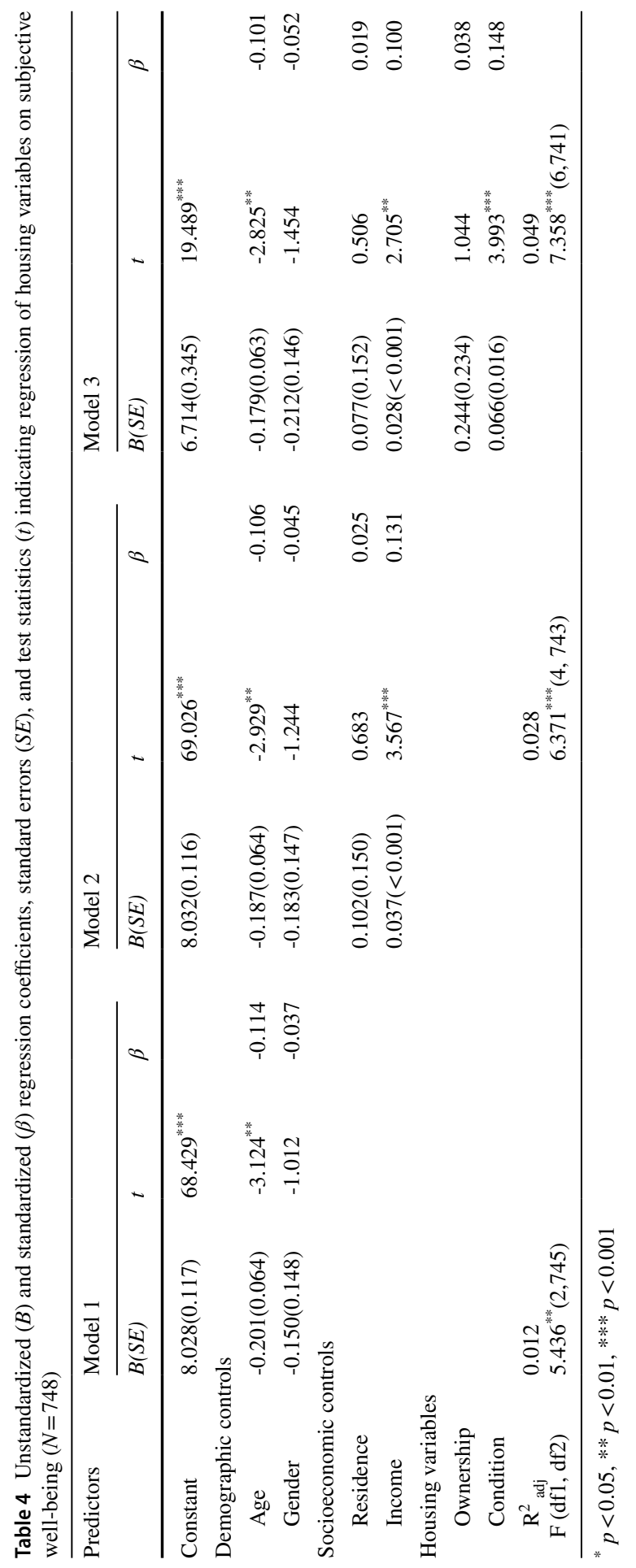


the regression model. In the first step, we entered age and gender as covariates in model 1 , then we added residence and family income in the past year in model 2 , and finally, we entered homeownership and housing conditions as the key predictors in model 3. The results of the regression models are shown in Table 4.

The results showed that after controlling for age, gender, residence, and family income, housing conditions significantly predicted children's depression $(\beta=0.148$, $t=3.993, p<0.001)$; the better the housing conditions that children lived in, the higher the level of children's subjective well-being. Subjective well-being was not significantly predicted by homeownership $(\beta=0.038, t=1.044, p=0.300)$. In terms of the demographic variables, age was a significant predictor of children's subjective well-being $(\beta=-0.101, t=-2.825, p=0.005)$, which suggested that as age increased, children's subjective well-being decreased. Family income was significantly associated with children's subjective well-being $(\beta=0.100, t=2.705, p=0.007)$, indicating that children from families with higher incomes were significantly happier than children from poorer families.

\section{Regression Analysis of Housing And Depression}

To examine the contribution of housing and homeownership to children's depression, we regressed depression on housing conditions and homeownership after controlling for demographic variables (age and gender) and socioeconomic variables (residence and family income). Homeownership, gender, and residence were dummy coded. Housing conditions, family income, and age were mean-centered. The results of the regression models are shown in Table 5.

After controlling for age, gender, residence, and family income, housing conditions significantly predicted children's depression, which means that the worse the housing conditions that the children lived in were, the higher the level of depression they experienced $(\beta=-0.074, t=-3.009, p=0.003)$. Depression was not significantly predicted by homeownership $(\beta=0.026, t=1.090, p=0.276)$. In terms of demographic and socioeconomic indicators, only age was a significant predictor of children's depression $(\beta=0.079, t=3.308, p<0.001)$, which suggested that as age increased, children's level of depression increased.

\section{The Effect of Housing in Rural and Urban Areas in China}

In the following analysis, we tested the effect of housing among adolescents from rural areas and urban areas (Table 6). First, we regressed urban adolescents' and rural adolescents' subjective well-being on housing variables after controlling for demographic variables (age and gender) and socioeconomic variables (residence, family assets, and family income). For adolescents from rural areas, the results showed that after controlling for age, gender, and family income, housing conditions were significantly associated with subjective well-being $(\beta=0.155, p=0.001)$; that is, the better the housing conditions were, the happier that rural adolescents felt. Homeownership and family income did not significantly predict rural children's subjective well-being. For children from urban areas, the effect of housing conditions 


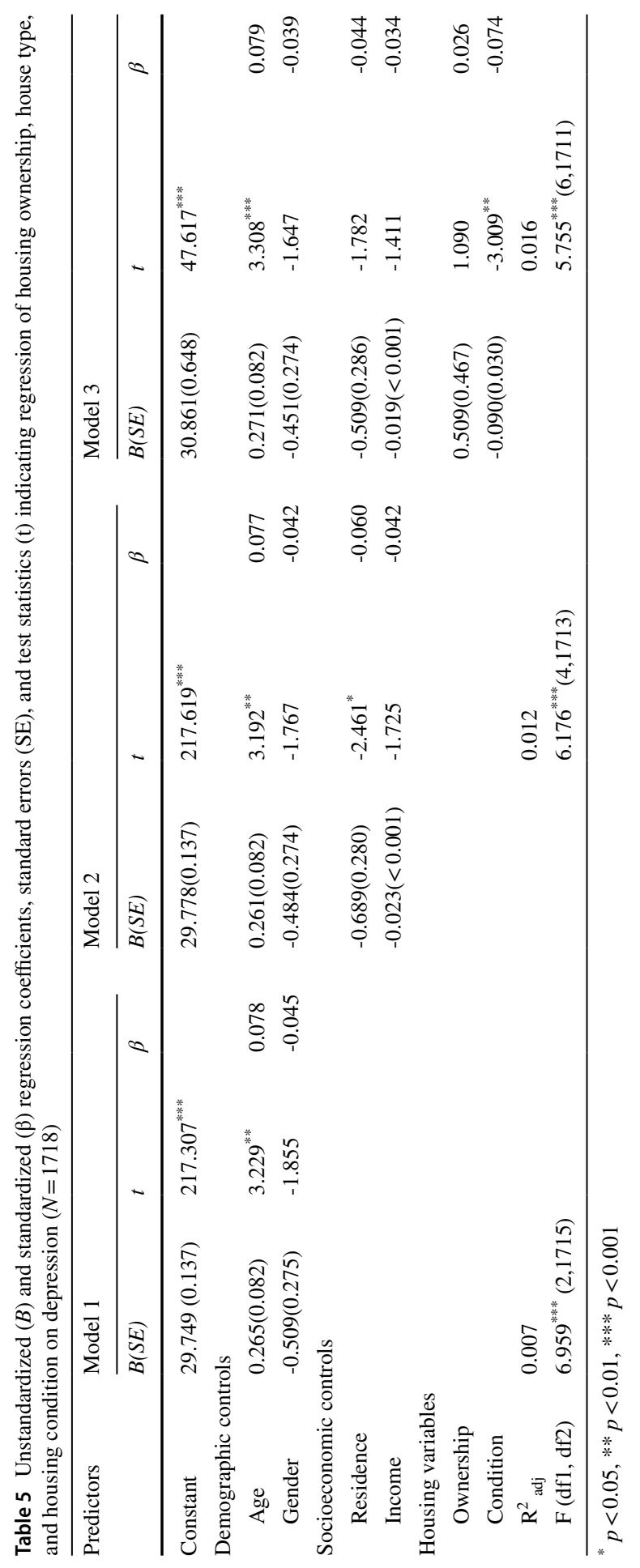


Table 6 Standardized $(\beta)$ regression coefficients indicating regression of housing variables on rural and urban adolescents' depression and subjective well-being

\begin{tabular}{llllll}
\hline & \multicolumn{2}{l}{ Depression } & & \multicolumn{2}{l}{ Subjective well-being } \\
\cline { 2 - 3 } \cline { 5 - 6 } Predictors & Rural & Urban & & Rural & Urban \\
\hline Age & $0.067^{*}$ & $0.100^{* *}$ & & $-0.132^{* *}$ & -0.049 \\
Gender & $-0.087^{* *}$ & 0.030 & & -0.023 & -0.101 \\
Income & 0.001 & -0.060 & & 0.073 & $0.138^{*}$ \\
Ownership & -0.011 & 0.066 & & 0.045 & 0.040 \\
House condition & $-0.067^{* *}$ & $-0.087^{*}$ & & $0.155^{* * *}$ & $0.125^{*}$ \\
$\mathrm{R}^{2}$ adj & 0.012 & 0.018 & & 0.045 & $0.044^{* *}$ \\
$F($ df1, df2) & $3.405^{* *}(5,976)$ & $3.630^{* *}(5,730)$ & & $4.977^{* * *}(5,420)$ & $3.977^{* *}(5,316)$ \\
\hline
\end{tabular}

${ }^{*} p<0.05, * * p<0.01, * * * p<0.001$

on their subjective well-being was also significant $(\beta=0.125, p=0.029)$. The better the housing conditions were, the happier that urban adolescents felt. In addition, unlike rural children, urban children's subjective well-being was associated with family income, which indicated that the higher the income was, the happier urban adolescents felt $(\beta=0.138, p=0.016)$.

Similarly, we also regressed urban adolescents' and rural adolescents' depression on housing variables after controlling for demographic variables (age and gender) and socioeconomic variables (family income). The regression coefficients are shown in Table 6. For adolescents from rural areas, the results showed that after controlling for age, gender, and family income, housing conditions were significantly associated with depression $(\beta=-0.067, p=0.037)$. For adolescents from urban areas, housing conditions were also negatively associated with depression $(\beta=-0.087, p=0.019)$. These results indicated that the better housing conditions were, the lower urban children's level of depression. In addition, we found that residence did neither moderate the relationship of housing and depression nor the relationship between housing and subjective well-being.

\section{The Mediating Effect of Self-Esteem on the Relationship of Housing Conditions and Subjective Well-Being and Depression}

To further analyze the relations among housing, self-esteem, subjective well-being, and depression, the study conducted a mediation effect analysis. Self-esteem was regarded as a mediator between the relationship of housing conditions and subjective well-being and between the relationship of housing conditions and depression. The mediating effect was analyzed using the PROCESS macro in SPSS (Preacher \& Hayes, 2008). The sample size of the bootstrap analysis was 5000. The results of the analyses are presented in Figs. 1 and 2, and the summary of PROCESS for the two mediation models is reported in Table 7.

Two observations can be highlighted in Table 7. First, the indirect effect of housing conditions on subjective well-being was $0.006(\mathrm{LLCI}=0.001, \mathrm{ULCI}=0.013$ ). The direct effect of housing conditions on subjective well-being was 0.076 


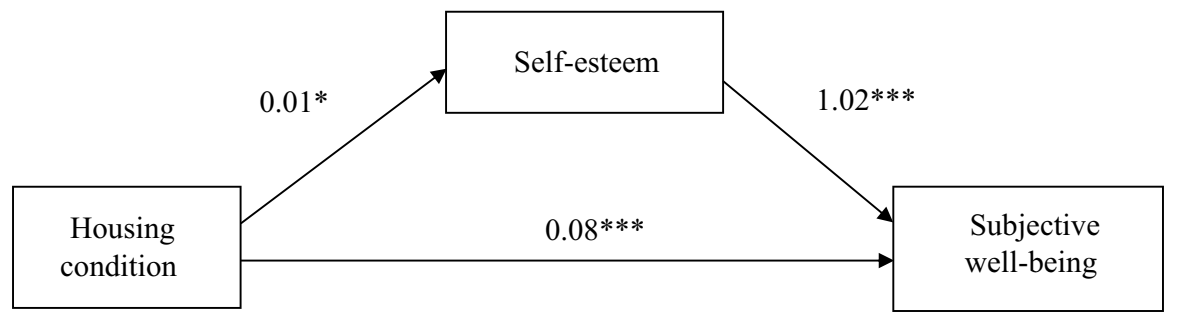

Fig. 1 Relationships among housing condition, self-esteem, and subjective well-being

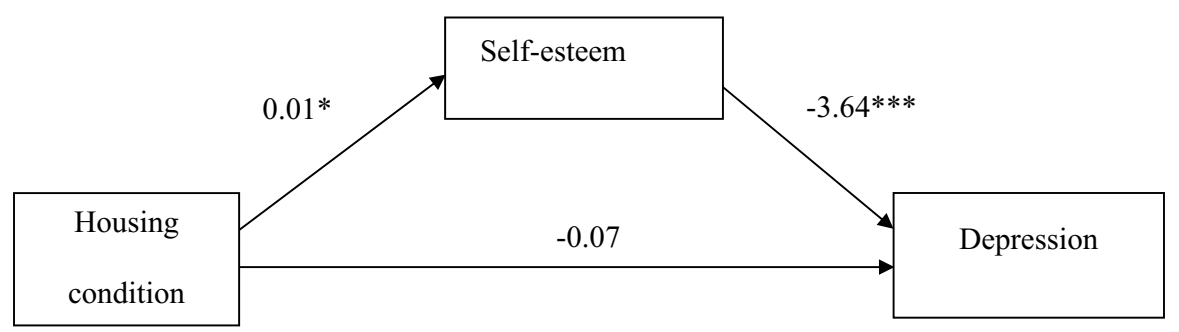

Fig. 2 Relationships among housing condition, self-esteem, and depression

$(\mathrm{LLCI}=0.048, \mathrm{ULCI}=0.104)$. The $95 \%$ confidence intervals of the indirect and direct effects do not contain 0 . The results showed a significant mediating effect of self-esteem on the relationship between housing conditions and adolescent subjective well-being. Second, the indirect effect of housing conditions on depression was -0.023 (LLCI $=-0.046, \mathrm{ULCI}=-0.002$ ). The direct effect of housing conditions on depression was $-0.069(\mathrm{LLCI}=-0.146, \mathrm{ULCI}=0.008)$. The $95 \%$ confidence interval of the direct effect contains 0 ; therefore, a complete mediating effect of self-esteem on the relationship of housing conditions and depression was found. In conclusion, the mediation analysis showed a significant mediating effect of self-esteem on the link from housing conditions to socioemotional well-being.

\section{Discussion}

The present study analyzed the impact of housing on Chinese adolescents' socioemotional well-being using nationally representative data from the CFPS 2016. To our knowledge, this study is one of the pioneering studies examining the relationship between housing and adolescents' subjective well-being and depression in China using large-scale data. The results showed that housing condition has a positive predictive effect on adolescents' socioemotional well-being. Specifically, housing conditions were significantly associated with adolescents' depression and subjective well-being. Self-esteem mediated the relationship between housing conditions and subjective well-being and the relationship between housing conditions and depression. However, homeownership did not predict adolescents' socioemotional outcomes. 


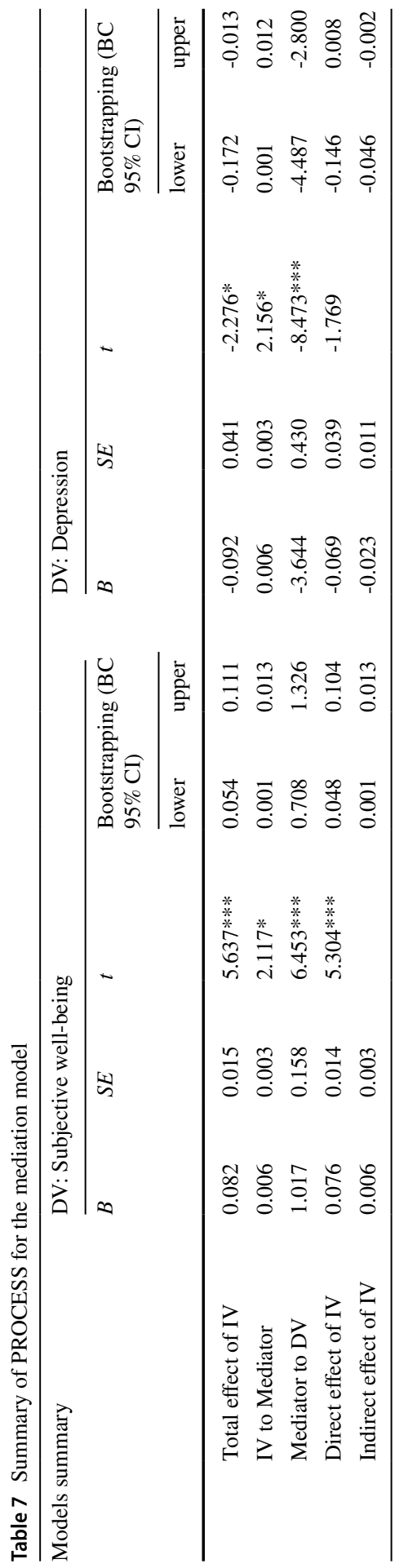


The national CFPS survey provides representative data on child well-being, which helped us investigate the effect of housing on Chinese adolescents. The results align with most of the results of past research in Western countries (Bradshaw et al., 2013; Rees \& Bradshaw, 2017), which suggested that housing conditions were positively related to child development. For example, Coley et al. (2013) found that housing quality predicted children's behavioral problems using representative longitudinal data in the United States. The reason that housing was associated with child well-being has been discussed in different ways. First, a commonly used theoretical model researchers used to explain housing's effect on child well-being was the bioecological model of human development (Bronfenbrenner, 1979; Bronfenbrenner \& Morris, 2006). The bioecological model suggested that the home environment is a critical distal context that children directly interact with, and housing features can directly or indirectly influence children's development. In addition, this theory stresses the interaction of individuals and the environment; that is, individual characteristics also play a role when housing impacts individual growth. The characteristics of the contexts and the individual characteristics are combined to impact the proximal processes and consequently influence children's development (Coley et al., 2013). The present study provided support for the bioecological model. The significant mediating effect of self-esteem on the relationship of housing conditions and socioemotional factors indicated that better housing conditions lead to a higher level of self-esteem, which consequently increases subjective well-being and lowers depression.

The economic perspective emphasizes the importance of family economic wellbeing as an important factor in children's development. The family investment model suggests that a high level of income enables families to purchase services, material goods, and even experiences that are helpful for children's healthy development (Linver et al., 2002; Yeung et al., 2002). Another family stress model proposes that family economic hardships are related to parental distress and partner conflict, which should result in lower-quality parenting and interaction with children (Conger et al., 1995, 2002; Elder \& Caspi, 1988; McLoyd et al., 1994). However, our data found homeownership did not predict adolescents' socioemotional outcomes. This finding is consistent with the studies on Western children (Holupka \& Newman, 2012) and concurs with the conclusion from Leventhal and Newman (2010) in a systematic review of housing and child development.

Although the existing evidence shows that housing problems are related to children's outcomes, the impact of housing on children's well-being needs to be discussed further. The main contribution of this research is in the discussion of the relationship between housing conditions and adolescent well-being. First, previous literature on the relationship between housing and children's well-being has mainly been conducted in developed countries, but there is little relevant experience and evidence in developing countries. This is pioneering research on the relationship between housing and adolescents' psychological development in China. Second, because there is still no conclusion on the empirical evidence regarding the relationship between housing and adolescents' socioemotional well-being, the current findings provide evidence of how housing impacts child development. In addition, most research on children and housing has been based 
on urban samples. The present study used a more diversified sample, including children from middle- and low-income families and rural areas, to systematically investigate the well-being of Chinese children at the ages of 10 to 15 . Finally, the present study found a mediating effect of self-esteem on the relationship between housing conditions and socioemotional well-being, and this mechanism underlying the effect of housing also lends support to the bioecological model. Children spend considerable time at home and are vulnerable to contextual factors (Shonkoff \& Phillips, 2000); therefore, the mechanism allows the family and policymakers to pay attention to the effects of housing on children's and adolescents' healthy development.

There are two implications of the present study. First, our findings suggest that good housing policies are important for adolescents' socioemotional development. Governments should provide affordable housing and improve the housing conditions for adolescents from poor families so that they face fewer risk factors that are detrimental to their development. Second, the mediating role of self-esteem reveals the importance of promoting social competence among adolescents. In fact, the findings suggest that adolescents living in poor housing conditions could still have healthy and positive development if they have a high level of self-esteem. Researchers have designed positive youth development programs to improve adolescents' social competence and positive self-identity, such as Project P.A.T.H.S. in Hong Kong and mainland China (Ma et al., 2019; Qi et al., 2020; Shek \& Zhu, 2020). As we found rural adolescents' socioemotional well-being is worse than urban children's because they are facing economic and family-related risky factors (Zhou et al., 2020a, b, c), applying such projects to adolescents from poor families and rural areas is paramount.

Although the present study has made some contributions to explore the impact of housing conditions on children's well-being, it still has several limitations. First, the present study used cross-sectional data for the analysis. It is necessary to study the long-term impact of low-quality housing on children using longitudinal data and examine the causal relationship between housing and child development. A future study can analyze the longitudinal data of the CFPS to examine the enduring effect of housing on child depression and subjective well-being. The second limitation was that the effect sizes of the direct and indirect effects of housing on subjective well-being and depression were low, and we should be cautious to avoid overinterpretation of the findings because statistical significance does not ensure practical significance (Rosen \& DeMaria, 2013). In addition, The mechanisms underlying the relationship between housing and child well-being still need further investigation and replication.

Funding This paper was financially supported by the Fundamental Research Funds for the Central Universities 2020 (330600004007000005) of Southwestern University of Finance and Economics, China.

\section{Declarations}

Conflicts of Interest The authors declare that they have no conflict of interest. 
Open Access This article is licensed under a Creative Commons Attribution 4.0 International License, which permits use, sharing, adaptation, distribution and reproduction in any medium or format, as long as you give appropriate credit to the original author(s) and the source, provide a link to the Creative Commons licence, and indicate if changes were made. The images or other third party material in this article are included in the article's Creative Commons licence, unless indicated otherwise in a credit line to the material. If material is not included in the article's Creative Commons licence and your intended use is not permitted by statutory regulation or exceeds the permitted use, you will need to obtain permission directly from the copyright holder. To view a copy of this licence, visit http://creativecommons.org/licen ses/by/4.0/.

\section{References}

Bradshaw, J., Martorano, B., Natali, L., \& Neubourg, C. (2013). Children's subjective well-being in rich countries. Child Indicators Research, 6(4), 619-635. https://doi.org/10.1007/s12187-013-9196-4

Bradshaw, J. (2015). Subjective well-being and social policy: Can nations make their children happier? Child Indicators Research, 8(1), 227-241. https://doi.org/10.1007/s12187-014-9283-1

Bronfenbrenner, U. (1979). The ecology of human development. Harvard University Press.

Bronfenbrenner, U., \& Morris, P. A. (2006). The bioecological model of human development. In W. Damon \& R. M. Lerner (Eds.), Handbook of child psychology (6th ed., Vol. 1, pp. 793-828). Wiley.

Cairney, J. (2005). Housing tenure and psychological well-being during adolescence. Environment and Behavior, 37, 552-564. https://doi.org/10.1177/0013916504270697

Clair, A. (2019). Housing: An Under-Explored influence on children's Well-Being and becoming. Child Indicator Research, 12, 609-626. https://doi.org/10.1007/s12187-018-9550-7

Cheng, C. Y. (1986). The concept of face and its Confucian roots. Journal of Chinese Philosophy, 13, 329-348. https://doi.org/10.1111/j.1540-6253.1986.tb00102.x

Coley, R. L., Leventhal, T., Lynch, A. D., \& Kull, M. (2013). Relations between housing characteristics and the well-being of low-income children and adolescents. Developmental Psychology, 49(9), 1775-1789. https://doi.org/10.1037/a0031033

Conger, R. D., Patterson, G. R., \& Ge, X. (1995). It takes two to replicate: A mediational model for the impact of parents' stress on adolescent adjustment. Child Development, 66, 80-97. https://doi.org/ 10.1111/j.1467-8624.1995.tb00857.x

Conger, R. D., Wallace, L. E., Sun, Y., Simons, R. L., McLoyd, V. C., \& Brody, G. H. (2002). Economic pressure in African American families: A replication and extension of the family stress model. Developmental Psychology, 38(2), 179-193. https://doi.org/10.1037/0012-1649.38.2.179

Diener, E. (1984). Subjective well-being. Psychological Bulletin, 95(3), 542-575. https://doi.org/10. 1007/978-90-481-2350-6_2

Dolan, P., Peasgood, T., \& White, M. (2008). Do we really know what makes us happy? A review of the economic literature on the factors associated with subjective well-being. Journal of Economic Psychology, 29(1), 94-122. https://doi.org/10.1016/j.joep.2007.09.001

Dong, L. M., \& Guo, J. X. (2017). Face belief in rural society and rural governance (Chinese). Chinese Social Sciences, 8, 147-160.

Edin, K., DeLuca, S., \& Owen, A. (2012). Constrained compliance: Solving the puzzle of MTO's leaseup rates and why mobility matters. Cityscape: A Journal of Policy Development and Research, 14, $181-194$.

Elder, G. H., \& Caspi, A. (1988). Economic stress in lives: Developmental perspectives. Journal of Social Issues, 44(4), 25-45.

Evans, G., Saltzman, H., \& Cooperman, J. (2001). Housing Quality and Children's Socioemotional Health. Environment and Behavior, 33, 389-399. https://doi.org/10.1177/00139160121973043

Evans, G., Lercher, P., \& Kofler, W. (2002). Crowding and children's mental health: The role of house type. Journal of Environmental Psychology, 22, 221-231. https://doi.org/10.1006/jevp.2002.0256

Fowler, P. J., Henry, D. B., \& Marcal, K. E. (2015). Family and housing instability: Longitudinal impact on adolescent emotional and behavioral well-being. Social Science Research, 53, 364-374. https:// doi.org/10.1016/j.ssresearch.2015.06.012

Gifford, R. \& Lacombe, C.(2006). Housing quality and children's socioemotional health. Journal of Housing and the Built Environment, 21, 177-189. https://doi.org/10.1007/s10901-006-9041-x 
Goux, D., \& Maurin, E. (2004). The effect of overcrowded housing on children's performance at school. Journal of Public Economics, 89(5), 797-819. https://doi.org/10.1016/j.jpubeco.2004.06.005

Harkness, J., \& Newman, S. J. (2005). Housing affordability and children's well-being: Evidence from the national survey of America's families. Housing Policy Debate, 16(2), 223-255. https://doi.org/ $10.1080 / 10511482.2005 .9521542$

Harville, E. W., \& Rabito, F. A. (2018). Housing conditions and birth outcomes: The national child development study. Environmental Research, 161, 153-157. https://doi.org/10.1016/j.envres.2017.11.012

Henrich, J., Heine, S. J., \& Norenzayan, A. (2010). The weirdest people in the world? Behavioral and Brain Sciences, 33(2-3), 61-83. https://doi.org/10.1017/S0140525X0999152X

Holupka, C. S., \& Newman, S. J. (2012). The effects of homeownership on children's outcomes: real effects or self-selection? Real Estate Economics, 3(40), 566-602. https://doi.org/10.1111/j.15406229.2012.00330.x

Hu, F. (2013). Homeownership and Subjective well-being in urban China: Does owning a house make you happier? Social Indicators Research, 110(3), 951-971. https://doi.org/10.1007/s11205-011-9967-6

Huang, J. (2018). Housing Poverty and Children's Learning: A Reproduction Path of Stratum (Chinses). Sociological Review of China, 6(6), 57-70. https://doi.org/10.3969/j.issn.2095-5154.2018.06.005

Huang, J., \& Wang, Z. (2017). Verseas review of housing conditions' effect on the children academic achievements (Chinese). Journal of Fujian Jiangxia University, 7(5), 75-82. CNKI:SUN:FCGY.0.2017-05-009.

Hwang, K. K., et al. (2010). Favor and face: The Chinese power game. Renmin University Publication.

Jelleyman, T., \& Spencer, N. (2008). Residential mobility in childhood and health outcomes: A systematic review. Journal of Epidemiology and Community Health, 62(7), 584-592. https://doi.org/10. 1136/jech.2007.060103

Leung, J.T.Y. \& Fung, A.L. (2021). Editorial: Special Issue on Quality of Life among Children and Adolescents in Chinese Societies. Applied Research Quality Life. https://doi.org/10.1007/ s11482-021-09915-9

Leventhal, T., \& Newman, S. (2010). Housing and child development. Children and Youth Service Review, 32, 1165-1174. https://doi.org/10.1016/j.childyouth.2010.03.008

Linver, M. R., Brooks-Gunn, J., \& Kohen, D. E. (2002). Family processes as pathways from income to young children's development. Developmental Psychology, 38(5), 719-734. https://doi.org/10.1037/ 0012-1649.38.5.719

Ma, C. M. S., Shek, D. T. L., \& Chen, J. M. T. (2019). Changes in the participants in a communitybased positive youth development program in Hong Kong: Objective outcome evaluation using a one-group pretest-posttest design. Applied Research Quality Life, 14(4), 961-979. https://doi.org/10. 1007/s11482-018-9632-1

McLoyd, V. C., Jayaratne, T. E., Ceballo, R., \& Borquez, J. (1994). Unemployment and work interruption among African American single mothers: Effects on parenting and adolescent socioemotional functioning. Child Development, 65(2), 562-589. https://doi.org/10.1111/j.1467-8624.1994.tb00769.x

Newman, S. (2008). Does housing matter for poor families? A critical summary of research and issues still to be resolved. Journal of Policy Analysis and Management, 27, 895-925.

Newman, S., \& Holupka, S. (2014). Housing affordability and investment in children. Journal of Housing Economics, 24, 89-100. https://doi.org/10.1016/j.jhe.2013.11.006

Newman, S. J., \& Holupka, C. S. (2015). Housing affordability and child well-being. Housing Policy Debate, 25(1), 116-151. https://doi.org/10.1080/10511482.2014.899261

Newman, S. J., \& Holupka, C. S. (2016). The Effects of Assisted Housing on Child Well-Being. American Journal of Community Psychology, 60(1), 66-78. https://doi.org/10.1002/ajcp.12100

OECD. (2009). Doing better for children. Paris: OECD. Retrieved from http://www.oecd.org/social/family/doingbetterforchildren.htm. Accessed 1 Jul 2020.

Preacher, K. J., \& Hayes, A. F. (2008). Asymptotic and resampling strategies for assessing and comparing indirect effects in multiple mediator models. Behavior Research Methods, 40, 879-891. https://doi. org/10.3758/BRM.40.3.879

Qi, S., Hua, F., Zhou, Z., \& Shek, D. T. (2020). Trends of positive youth development publications (1995-2020): A scientometric review. Applied Research in Quality of Life, 1-26. https://doi.org/10. 1007/s11482-020-09878-3

Radloff, L. S. (1977). The CES-D scale: A self-report depression scale for research in the general population. Applied Psychological Measurement, 1(3), 385-401. https://doi.org/10.1177/0146621677 00100306 
Rees, G., \& Bradshaw, J. (2017). Exploring low subjective well-being among children aged 11 in the UK: An analysis using data reported by parents and by children. Child Indicators Research, 11, 27-56. https://doi.org/10.1007/s12187-016-9421-z

Rollings, K. A., Wells, N. M., Evans, G. W., Bednarz, A., \& Yang, Y. (2017). Housing and neighborhood physical quality: Children's mental health and motivation. Journal of Environmental Psychology, 50, 17-23. https://doi.org/10.1016/j.jenvp.2017.01.004

Rosen, B. L., \& DeMaria, A. L. (2013). Statistical significance vs. practical Significance An exploration through health education. American Journal of Health Education, 43(4), 235-241. https://doi.org/ 10.1080/19325037.2012.10599241

Sandel, M., \& Wright, R. J. (2006). When home is where the stress is: Expanding the dimensions of housing that influence asthma morbidity. Archives of Disease in Childhood, 91, 942-948. https:// doi.org/10.1136/adc.2006.098376

Sandra, N., \& Tama, L. (2018). The housing and children's healthy development study. Cityscape: A Journal of Policy Development and Research, 20(3), 237-244.

Shek, D. T. L. (2010). Introduction: Quality of life of Chinese people in a changing world. Social Indicators Research, 95(3), 357-361. https://doi.org/10.1007/s11205-009-9534-6

Shek, D. T. L. (2014). Applied Research in Quality of Life (ARQOL): Where Are We and Issues for Consideration. Applied Research Quality Life, 9, 465-468. https://doi.org/10.1007/s11482-014-9340-4

Shek, D. T. L., \& Siu, A. M. H. (2019). "Unhappy" environment for adolescent development in Hong Kong. Journal of Adolescent Health, 64(6S), S1-S4. https://doi.org/10.1016/j.jadohealth.2019.01. 007

Shek, D. T. L., \& Zhu, X. Q. (2020). Promotion of thriving among Hong Kong Chinese adolescents: Evidence from eight-wave data. Research on Social Work Practice, 30(8), 870-883. https://doi.org/10. $1177 / 1049731520947156$

Shenassa, E. D., Stubbendick, A., \& Brown, M. J. (2004). Social disparities in housing and related pediatric injury: A multilevel study. American Journal ofPublic Health, 94, 633-639.

Shonkoff, J. P., \& Phillips, D. A. (Eds.). (2000). From neurons to neighborhoods: The science of early child development. National Academy of Sciences.

Solari, C. D., \& Mare, R. D. (2012). Housing crowding effects on children's well-being. Social Science Research, 41(2), 464-476. https://doi.org/10.1016/j.ssresearch.2011.09.012

UNICEF. (2007). Child poverty in perspective: an overview of child well-being in rich countries. Florence: Unicef. Retrieved from: https://www.unicef.org/media/files/ChildPovertyReport.pdf. Accessed $1 \mathrm{Jul} 2020$.

UNICEF. (2013). Child well-being in rich countries: A comparative overview. Florence: Unicef. Retrieved from: https://www.unicef-irc.org/publications/pdf/rc11_eng.pdf. Accessed 1 Jul 2020.

UNICEF. (2016). Fairness for Children A league table of inequality in child well-being in rich countries. Florence: Unicef. Retrieved from: https://www.unicef-irc.org/publications/pdf/RC13_eng.pdf. Accessed 1 Jul 2020.

Wang, S. Y. (2011). State misallocation and housing prices: Theory and evidence from China. American Economic Review, 101(5), 2081-2107.

Wang, M., Xu, Q., \& He, N. (2021). Perceived interparental conflict and problematic social media use among Chinese adolescents: The mediating roles of self-esteem and maladaptive cognition toward social network sites. Addictive Behaviors, 112, 106601. https://doi.org/10.1016/j.addbeh.2020. 106601

Weitzman, M., Baten, A., Rosenthal, D. G., Hoshino, R., Tohn, E., \& Jacobs, D. E. (2013). Housing and child health. Current Problems in Pediatric and Adolescent Health Care, 43(8), 187-224. https:// doi.org/10.1016/j.cppeds.2013.06.001

Wells, N. M., \& Harris, J. D. (2007). Housing quality, psychological distress, and the mediating role of social withdrawal: A longitudinal study of low-income women. Journal of Environmental Psychology, 27(1), 69-78. DOI: 10.1016/j.jenvp.2006.11.002Wu, W., Stephens, M., Du, M., \& Wang, B. (2019). Homeownership, family composition and subjective wellbeing. Cities, 84, 46-55. https:// doi.org/10.1016/j.cities.2018.07.004

Yeung, W. J., Linver, M. R., \& Brooks-Gunn, J. (2002). How money matters for young children's development: Human capital and family process. Child Development, 73(6), 1861-1879. https://doi.org/ 10.1111/1467-8624.t01-1-00511

Zhou, Q., Guo, S. \& Lu, H. J. (2020). Well-Being and health of children in rural China: the roles of parental absence, economic status, and neighborhood environment. Applied Research of Quality Life. https://doi.org/10.1007/s11482-020-09859-6 
Zhou, Z., Shek, D. T. L., \& Zhu, X. (2020b). The importance of positive youth development attributes to life satisfaction and hopelessness in mainland Chinese adolescents. Frontiers in Psychology, 11, 553313. https://doi.org/10.3389/fpsyg.2020.553313

Zhou, Z., Shek, D. T. L., Zhu, X., \& Dou, D. (2020c). Positive youth development and adolescent depression: A longitudinal study based on Mainland Chinese high school students. International Journal of Environmental Research and Public Health, 17, 4457. https://doi.org/10.3390/ijerph17124457

Publisher's Note Springer Nature remains neutral with regard to jurisdictional claims in published maps and institutional affiliations. 